\title{
Health services and the public health
}

\section{J Donaldson}

J Epidemiol Community Health 2002;56:835-840

The 16th Duncan Memorial Lecture. Given at Henry Cohen lecture theatre, Duncan Building, Daulby Street, Liverpool, UK on Wednesday 25 November 1998 by Professor Sir Liam J Donaldson, Chief Medical Officer for England.

M any modern public health practitioners become drawn to the origins of public health as a discipline, and turn their attention first to sources of local history within their jurisdiction. It was in this way that John Ashton's curiosity was aroused, and he brought the story of William Henry Duncan to popular attention, inaugurating the Duncan Memorial Lecture Series. ${ }^{1}$

In fact, the career of John Snow, the Victorian public health pioneer, was of especial interest to the late Sidney Chave, who gave the lst Duncan Memorial Lecture. Chave consulted original historical sources to unravel the events surrounding Snow's part in combating the cholera outbreak in Golden Square, Soho, in 1854 . $^{2}$

Although John Snow (1813-1858) and William Duncan (1805-1863) were contemporaries, it is not known whether they ever met. Snow was born in York, and apprenticed as a surgeon in Newcastle upon Tyne. Apart from being one of the earliest anaesthetists, John Snow is famous for identifying the link between drinking water and cholera. He was able to persuade the guardians of the Parish of St James to remove the handle of the water pump in Broad Street, thereby hastening the decline of the cholera epidemic in that area, which had killed so many.

The first officially recorded case of cholera in England was in Sunderland in October 1831, although it is possible that some of the deaths that occurred earlier in that year had been caused by Asiatic cholera. ${ }^{3}$

Cholera first appeared in Newcastle upon Tyne during December 1831. William Hardcastle deputed John Snow, his former apprentice, to go to Killingworth Colliery where there was a severe outbreak. Snow's experience of cholera at Killingworth may have helped to formulate the ideas that led to his investigation and prevention of cholera in London 23 years later.

The first outbreak of cholera in Liverpool was in 1832 when Duncan was physician to the South Dispensary. Later Duncan was to become the first Medical Officer of Health (1847-1863), and had to contend with several severe outbreaks of cholera in Liverpool. ${ }^{5}$

Edward Headlam Greenhow (1814-1888), a contemporary of Duncan's and considered to be an authority on sanitary science, was involved in reporting on the sanitary state of the country to the Board of Health. ${ }^{6}$ He had thrown some discredit on the sanitary condition of Liverpool, and on the efforts made to improve it. In his annual report of 1860, Duncan pointed out the statistical inaccuracies in Greenhow's work, and refuted the conclusions drawn from them. ${ }^{5}$

Although Duncan was a pioneer in the practice of sanitation in a large and rapidly expanding town, he faced two main difficulties:

- the imperative to care for people who had diseases the causes of which were not fully understood;

- the lack of any direct locus in the control of local hospitals, and doctors and nurses.

The General Board and the Town Council, however, were impressed with Duncan's work, and he came to be regarded "as the administrator charged, in time of epidemics, with the duty of co-ordinating all the resources of the borough, whether in the possession of the council or not ${ }^{\prime \prime} .5$

From these historical vignettes, it can be seen that both Snow and Duncan had a healthcare dimension to their work-Snow through pioneering anaesthesia, and Duncan through organising the hospitals at times of crisis_although, during the 19th century, there was a marked separation between the provision of health services and public health. Indeed, the Public Health Act 1848 had formalised the division between the Poor Law and, by definition, the Poor Law Medical Services, and public health. In the administration of the Poor Law, there was a focus on reducing costs through deterrent, whereas the public health movement sought to achieve prevention and therefore incurred expenditure.?

\section{THE ROLE OF THE HEALTH SERVICE}

Having reached the 50th anniversary of the National Health Service, which provides a comprehensive system of medical care on the basis of need and largely free at the point of access, it is appropriate to review what we can expect from a health service.

In 1979, the Royal Commission on the NHS defined the role of the health service as follows:

- to encourage and assist individuals to remain healthy;

- to provide equality of entitlement to health services;

- to provide a broad range of services of a high standard;

- to provide equality of access to these services;

- to provide a service free at the time of use;

- to satisfy the reasonable expectations of its users;

- to remain a national service responsive to local needs. 
From the patient's perspective, s/he expects a health service to provide practical help and support when needed in the form of:

- a doctor or other healthcare professional who will listen to their problem or concern and try to give an explanation of it;

- clinical investigation to establish the nature of the illness or disease;

- where possible, an intervention to resolve the problem.

Increasingly, contact with patients will be used to give advice on maintaining and promoting health through lifestyle change.

\section{THE RELATION BETWEEN HEALTH SERVICES AND PUBLIC HEALTH}

The central theme for this lecture is the relation between health services and the public health that has been built up during the course of the 20th century. It is timely to address this issue now, 150 years after the Public Health Act 1848 laid the foundations for the sanitary reforms of the Victorian era, and for the widespread establishment of the post of medical officer of health.

In the past, the relation between health services and the public health tended to be focused only on the outcomes of care. Although the achievement of better outcomes for people being cared for within the health service does contribute to the population's overall health status, there are several key interfaces between public health and health services:

- delivering population public health goals;

- improving the outcome of care;

- reducing inequity;

- practising public health in a health service environment;

- evaluating health services.

\section{Delivering population public health goals through health services}

A traditional role of health services is to provide a delivery system for preventive services. One of the successes of this particular interface between health services and the public health is the steady increase in the uptake of immunisation among infants and young children. As new vaccine strategies have been introduced, they have prevented illness and handicap, and saved lives. However, problems remain in reaching all sections of the population, particularly those living in the most deprived communities of our towns and cities.
The degree of success of preventive services delivered through health services to tackle chronic diseases in adult life has been more limited. Pre-symptomatic screening is an intervention that has had a beneficial effect overall, for example, in preventing the incidence of cervical cancer, but there is variable performance in public health programmes. If the potential of screening programmes in preventing unnecessary deaths and ill health is to be realised, it is vital to tackle the complexities of delivering population based programmes in communities suffering from deprivation and high mortality, some of which may be culturally diverse.

However, seeking out healthy people to offer them the prospect of an early diagnosis is not necessarily beneficial to them, ethical, or cost effective. Therefore, it is necessary to ensure that with the advent of simple, cheap, non-invasive diagnostic technology, screening is not developed in an unregulated way simply because disease markers can be found easily. The National Screening Committee (NSC) issued its first report ${ }^{8}$ during the 50th anniversary of the NHS, and has already introduced a new discipline into public health policy making. One of the NSC's first actions was to advise the government that screening for prostate cancer should not be introduced at present because the research evidence currently available did not yet support the use of this intervention.

The challenge for the 2 lst century is to address population public health goals through health services by preventing diseases, such as coronary heart disease (CHD), which were uncommon in Duncan's day. CHD can be considered to be a modern epidemic, one that:

- affects disadvantaged communities disproportionately;

- has a complex causation;

- demands multifaceted action coordinated across several fronts.

These features of CHD are not dissimilar to the public health challenges posed by the infectious diseases prevalent during the 19th century (see fig 1).

In the UK, the new Labour government is addressing the new public health agenda, initially with the appointment of a Minister for Public Health, and the publication of a consultation paper-Our Healthier Nation ${ }^{9}$ - in which were set out two broad goals and the concept of contracts for health. These contracts identify responsibilities for action at various levels. Essential to this approach is cross-government working. In the first report of the Social Exclusion Unit, ${ }^{10}$ the common links between social, health, and economic disadvantage were highlighted and the importance of coordinated action and partnership working to find solutions was emphasised.

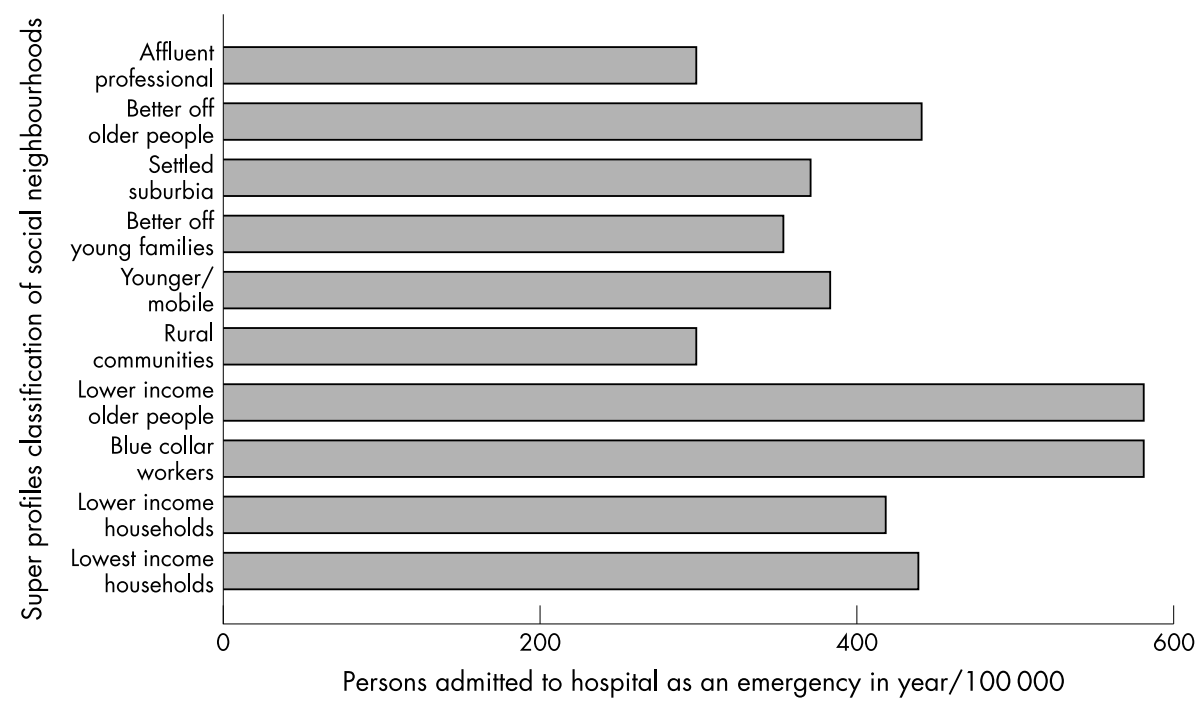

www.jech.com
Figure 1 Coronary heart disease in north west England, 1996/97. Source: Inequalities in health in the north west, Warrington: NHS Executive, 1998. 
Table 1 Changing approaches to partnerships

\begin{tabular}{|c|c|}
\hline "Previous" approaches & "Developing" approaches \\
\hline Top down approach & Think beyond categories of top down and bottom up \\
\hline Rely on formal organisation structures & Informal aspect of organisational life equally important \\
\hline Often set high initial stakes & Avoid high initial stakes \\
\hline Communications on tasks and agendas in hand & Communications over wide range of other issues \\
\hline Accountability clearer & Accountability more complex \\
\hline Shared perspectives & Individual perspectives \\
\hline Change management models to reach goals & Adaptation and learning models to reach goals \\
\hline
\end{tabular}

However, partnership working, whether at a central level among government departments or at a local level among different organisations and agencies, is not easy to achieve, and requires active development. Contemporary approaches to partnership are different to the joint planning models of the 1970s ( see table 1). Oversimplistic notions of "bottom up" and "top down", over-reliance on formal organisational structures, unduly pedantic attempts to determine precise accountability arrangements are largely outmoded. Approaches based on the creative use of formal and informal networks, innovative methods of communication, and a general emphasis on organisational adaptation and learning are the keys to building successful partnerships in future.

Local partnerships will be of value only if the guiding principle is to develop the communities that they serve so that improved health can be added to other regeneration goals such as better environment, greater inward investment, and higher employment levels.

The relation between health services and community development has its recent origins in the 1970s, although the roots reach further back to projects such as the establishment of a health centre in Peckham in the 1930s. ${ }^{11}$ Although there are many examples of successful community development, numerous community development projects have not proved to be sustainable, often because of a failure on the part of statutory services to fulfil their role in the partnership. There is now a renewed interest in the range of approaches that can be characterised as community development, which have a novel focus on sustainability and capacity building. ${ }^{12}$ Within local public health partnerships, addressing this new community development agenda will entail a strategic shift away from the management of contracts for services to the management of skills, influence, and networks.

\section{Improving the outcome of care}

The outcomes of health care contribute to the health status of a population, especially when so many people who suffer from chronic diseases, such as diabetes mellitus, can have their health and quality of life improved by well organised, effective care. Figure 2 shows the incidence of blindness varies between

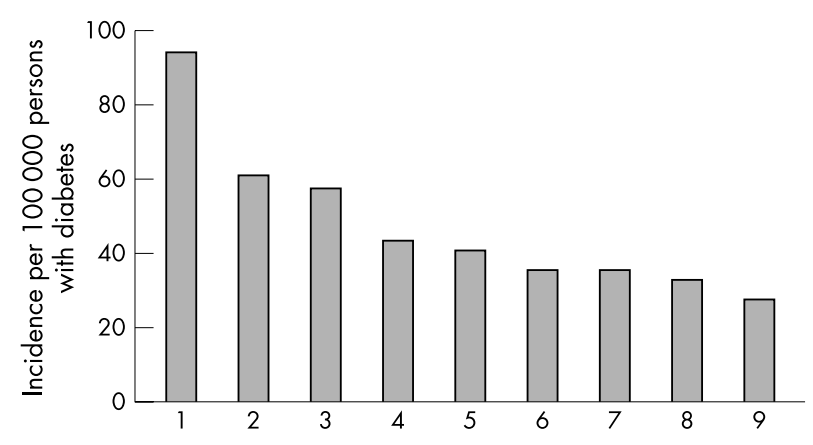

Figure 2 Diabetes mellitus - new cases of blindness in European countries. Source: The St Vincent National Liaison Persons. patients being cared for by different diabetic services and is a clear illustration of how avoidable adverse outcomes of care are dependent on the quality of service provided.

The ability of health services to deliver successful outcomes comprehensively is blighted by the variable performance and consequently variable opportunities for health among people who are ill.

There are about 1000 organisations that provide health care within the NHS in England responsible for spending $£ 35$ billion per year of the budget. One million staff, many of whom are doctors, nurses, or other healthcare professionals, work in these organisations. It has been estimated that about 40-50 million clinical decisions are taken per million population every year. ${ }^{13}$ These decisions involve the diagnosis of illness, its treatment, and the care of patients, and such decisions are the major determinants of the outcome of care for patients.

During 1998, public attention in the UK was focused on situations in which the outcomes of clinical decisions had gone seriously wrong and the care provided by the health services was not delivered at a standard that was acceptable. ${ }^{14}{ }^{15}$ The consequences of such failures are devastating for public confidence in health services.

It must be recognised that these events are rare in relation to the amount of excellent care delivered to a high standard in the NHS. Despite the rarity of such failures, the effect of each failure is considerable for the individual patient concerned, public confidence in health services, the reputation of the health care organisation involved, and on the morale and pride of the medical profession. It is vital to find a way to deal with the problem of poor quality as manifest in service failure.

In the past, most attention has been paid to individual error; however, it is also necessary to consider the organisational dimension of failures, incidents, or lapses. Across the spectrum of health care, much of the "evidence" about service failure is generated from many of the formal and informal inquiries that are carried out, and anecdotal accounts of those people who have extensive experience of dealing with such problems. As a sector, health care does not differ fundamentally from any others in which organisational failure occurs. The defining features of an organisation in which failure is likely to occur are:

- poor leadership;

- weak management systems;

- adverse culture.

If serious failures in the health service are to be avoided, it will be necessary to regard accountability for mistakes and lapses in the standard of care as organisational failures as well as poor performance on the part of an individual. ${ }^{14}{ }^{15}$ Organisational development will be an important element in eliminating such failures in future.

The government has set out a new quality agenda for the NHS in two companion documents-The new NHS: modern, dependable ${ }^{16}$ and $A$ first class service: quality in the new NHS. ${ }^{17}$ In particular, a statutory duty for quality has been established to redress the imbalance of the past when money and workload 


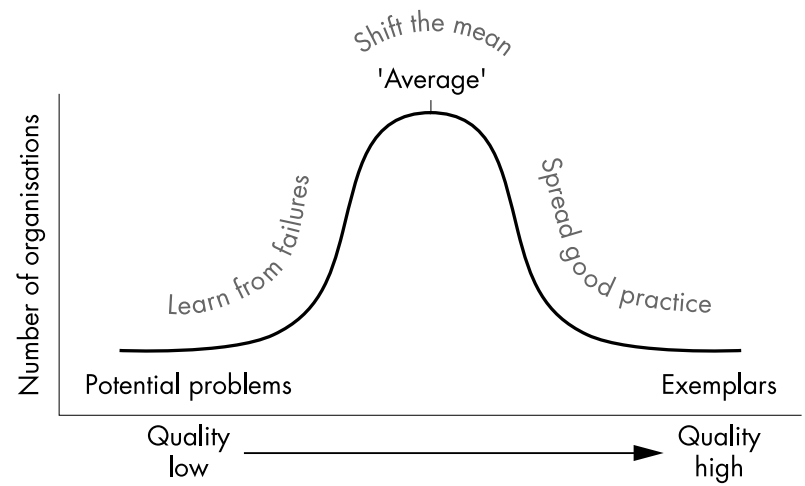

Figure 3 Variation in the quality of health care organisations. Source: Scally G, Donaldson L. Clinical governance and the drive for quality improvement in the new NHS in England. BM 1998;317:61-5.

targets were given greater prominence than quality in the strategic planning and policy development of healthcare organisations. At a local level, the concept of clinical governance provides the basis for clinicians to play a leading part in transforming individual healthcare organisations to ensure that continuous quality improvement is integral to the delivery of hospital and primary care services in the NHS. ${ }^{18}{ }^{19}$ If these mechanisms are effective, the quality of care will improve, and the culture will shift to one in which lessons are learnt from failures and in which good practice is spread throughout the service (see fig 3).

\section{Reducing inequity and variations}

Apart from inequity in health status (see fig 1), there is also inequity in health service delivery, and variable access to health services. This inequity is highlighted in figure 4 , which shows a marked variation in rates for coronary artery bypass grafting (CABG) in 15 health districts during 1991. At this time, there was one regional treatment centre funded to provide a service to residents in these districts, on an equitable basis. However, those residents who had the best access to services were living in District 15 in which the treatment centre was located, whereas those residents who had the poorest access lived in District 1, but which was a distance of only eight miles away. Moreover, the people in District 1 at that time were suffering from one of the worst levels of coronary heart disease mortality in the country.

Inequitable access to services is a common feature of health systems. The reasons for inequitable access are complex, and need to be tackled through rigorous public health analysis to highlight the problem, and strong policy making and planning to resolve it.

\section{Public health research and practice}

The NHS has been the working base for the majority of public health practitioners over the past 25 years. As such, public health practice has been interpreted through the structures and systems of the health service. Although previous reorganisations in the NHS may have diminished the profile and weight of the public health role, the discipline of public health has survived as a specialty of medical practice. Fortunately, today, the health service environment is more hospitable for public health practitioners.

However, there are major challenges facing public health practitioners and their role in the modern NHS, as follows:

- ensuring that recently introduced structures to the NHS, such as primary care groups/trusts (PCG/Ts), orientate effectively towards a new public health agenda;

- ensuring that health improvement programmes (HImPs) are based on a clear assessment of health need, and public health programmes are designed on the basis of good evidence;

- increasing the multidisciplinary nature of public health departments to facilitate the development of partnership working both within and outside the organisation;

- equipping many more people, apart from those who are medically qualified, with public health skills, and giving them clear roles and responsibilities within the system.

To meet these challenges will require a full assessment of the capacity and capability of the public health workforce.

\section{Evaluation of health services by public health}

Public health methodologies have a role in the evaluation of health services. Archie Cochrane, the first President of the Faculty of Public Health Medicine wrote the seminal monograph Effectiveness and Efficiency-random reflections on health services ${ }^{20}$ in which he urged the greatest rigour in determining which interventions were effective and which interventions were not in a health system in which millions of pounds and thousands of lives rest on clinical decision making. He advocated the use of the randomised controlled trial (RCT) as a means of evaluating the effectiveness of interventions. In fact, Cochrane's work laid the foundation for the evidence based approach that has begun to revolutionise clinical practice and healthcare management.

There are circumstances in which it is inappropriate to use an RCT:

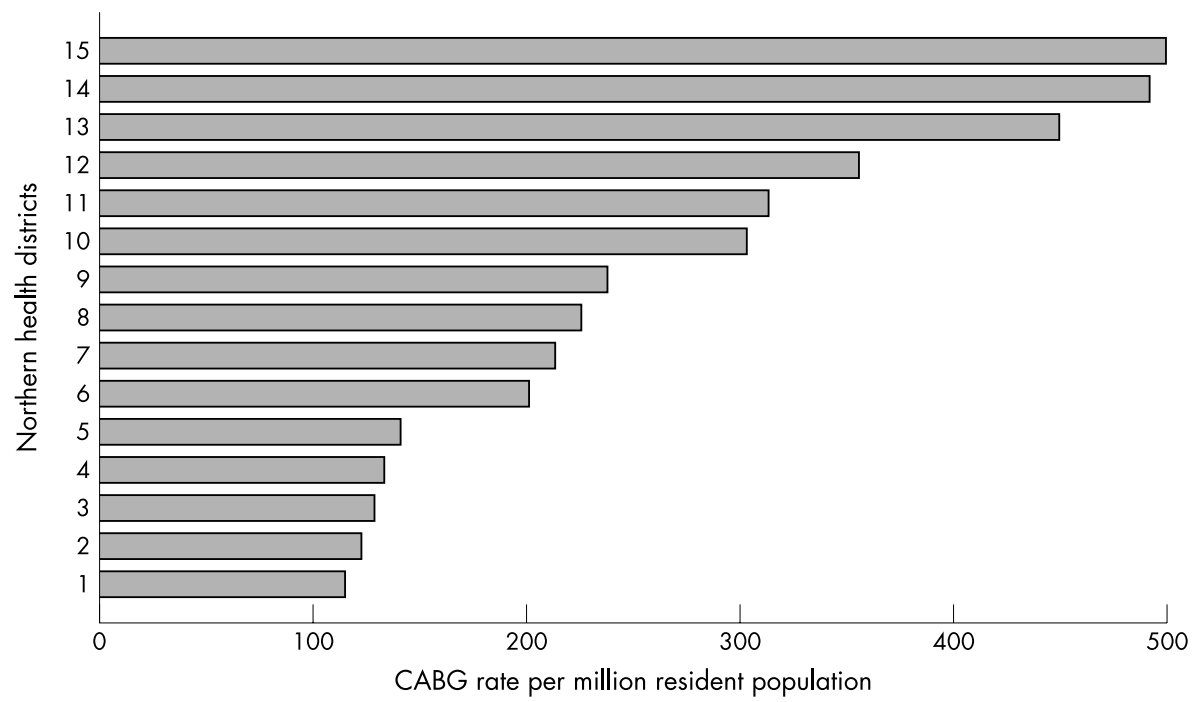

Figure 4 Coronary artery bypass graft rate per million resident population, 1991 


\begin{tabular}{|c|c|}
\hline Greater understanding & Practice implications \\
\hline $\begin{array}{l}\text { Aetiological } \\
\text { studies }\end{array}$ & $\begin{array}{l}\text { Eliminating and } \\
\text { modifying risk }\end{array}$ \\
\hline $\begin{array}{l}\text { Population surveys } \\
\text { (inc registers) }\end{array}$ & Assessing need \\
\hline $\begin{array}{l}\text { Presymptomatic } \\
\text { screening }\end{array}$ & $\begin{array}{l}\text { Regulating population } \\
\text { based screening }\end{array}$ \\
\hline $\begin{array}{l}\text { Health promotion } \\
\text { interventions }\end{array}$ & $\begin{array}{l}\text { Implementing strategies } \\
\text { to improve health }\end{array}$ \\
\hline $\begin{array}{l}\text { Medical care } \\
\text { evaluation }\end{array}$ & $\begin{array}{l}\text { Improving the quality } \\
\text { of health care }\end{array}$ \\
\hline
\end{tabular}

Figure 5 Improved public health practice-key shifts.

- to identify the adverse effects of intervention, especially if they occur infrequently;

- to determine the effects of an intervention that has been designed to prevent a rare event, for instance, sudden infant death;

- to evaluate the outcomes of intervention that are long term, such as in the use of hormone replacement therapy;

- to evaluate the effectiveness of an intervention when the application of random allocation could reduce its effectiveness, as is the case in psychotherapy.

In some circumstances, it may not be possible to conduct an RCT for any one of the following reasons:

- reluctance among clinicians to participate;

- ethical objections;

- political obstacles;

- legal constraints;

- randomisation is not possible;

- contamination, that is, behaviour in one RCT would affect that in another:

- scale.

Finally, the design and/or conduct of RCTs may not be sufficiently rigorous, and therefore the findings are unreliable for use as evidence in decision making.

Although RCTs have an important part to play in establishing the evidence base for intervention, a wide variety of other research methods (for example, aetiological studies, and population surveys) and traditions (for example, health promotion) produce evidence vital to the process of evaluating health services (see fig 5). An important goal for the future is to underpin the spectrum of public health practice with a strong evidence base.

\section{LOOKING BACK ON THE 20th CENTURY}

In reviewing the 20th century, particularly the second half, it can be seen that public health and health services in the UK have become closely intertwined. To gain an appreciation of the progress that has been made, it is illuminating to reflect on a conversation between Robert Coles, an American physician, and William Carlos Williams, an older colleague, and also a famous poet:

"I will never forget the sight of one particular ward in Massachusetts General Hospital in 1955, when a polio epidemic, (the last before the Salk vaccine came into use) spread through metropolitan Boston. I was a medical resident then, spending long hours with patients who had 'bulbar polio'. The ward that day was filled with row upon row of metal cylinders filled with people, their heads visible at one end. These were iron lungs, breathing for those housed inside whose

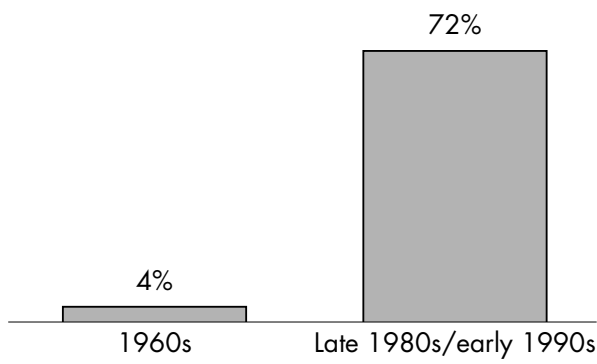

Figure 6 Five year survival rates for acute lymphoblastic leukaemia in children, Great Britain. Source: Stiller and Draper 1998. ${ }^{22}$

own breathing centre in the brain-stem was inactivated by the polio virus. It was a heart stopping sight. I described the scene to my older colleague, William Carlos Williams who was by then retired and ailing but his mind still sharp. His eyes widened and his face became animated. 'Take a picture or two,' he urged, 'it will all pass, it will all be gone by the time you're my age $^{\prime \prime}{ }^{\prime 21}$

Some of the public health problems of the past, such as polio, that resulted in hospital admission on a major scale have passed and gone, just as Williams predicted. Indeed, improvements in the care and survival of patients suffering from diseases for which the outcomes of treatment were uniformly poor only a few years ago, such as lymphoblastic leukaemia (see fig 6), can still be seen today. ${ }^{22}$ During the 20th century, innovations in the medical sciences, and the development of new treatments and technologies, have played an important part in improving the health status of the population as well as relieving the suffering of the individual patient (see fig 7).

\section{CONCLUSION}

The first person who can be recognised as fulfilling the role of Chief Medical Officer (CMO) was Sir John Simon. ${ }^{23}$ He made a great contribution to public health reform in the 19th century. It is ironic that one of the reasons for him resigning from the post was the proposal to transfer it to the Local Government Board thereby placing it under the parsimonious control of the Poor Law Director. The latter was responsible for providing the only state medical services for those unable to pay for private medical care. The provision of these medical services was based on the principle of "lesser eligibility", that is, the service provided was no better than, or at least as bad as, the worst that could be obtained by a private patient. It was this principle that Simon stood out against.

Today, the strength of the CMO's post is the capacity to straddle public health and the health services, helping all

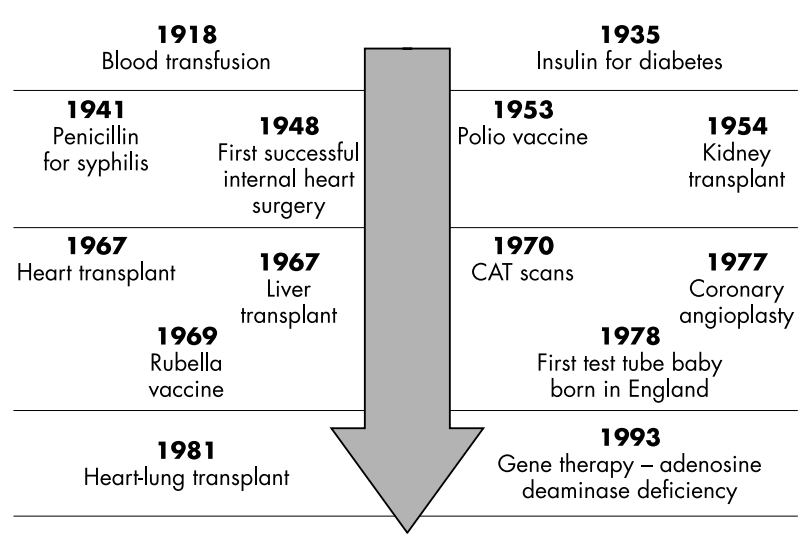

Figure 7 The march of progress. 
healthcare professionals to tackle the challenges presented by the five key interfaces between public health and health services that I have discussed in this paper.

As we enter the new millennium, we can draw inspiration from the Victorian public health movement-men like John Snow, William Henry Duncan, and Sir John Simon and women like Florence Nightingale. If we can embrace their purpose to tackle the root causes of ill health, be constant to their aim of galvanising concerted action from a broad range of interested parties, and keep faith with their ideals to rid society of suffering and inequity, then the outcomes will surely be a healthier population and a higher quality health service than we have today.

\section{REFERENCES}

1 Ashton JR. Health in our time? The William Henry Duncan Memorial Lectures. Preston: Carnegie Publishing, 1997.

2 Chave SPW. Duncan of Liverpool- and some lessons for today. London School of Hygiene and Tropical Medicine. Community Medicine 1984;6:61-71.

3 Kell JB. The appearance of cholera at Sunderland in 1831; with some account of that disease by James Butler Kell Esq. Surgeon to the Eighty Second Regiment. Edinburgh: Adam and Charles Black, 1834.

4 Snow J. On the mode and communication of cholera. 2nd edn. First edn London 1849; second edition, enlarged, London 1855; The whole was reprinted with introduction by Wade Hampton Frost, New York: Hafner Publishing, first published 1936 and reprinted 1965

5 Frazer WM. Duncan of Liverpool: being an account of the work of Dr W H Duncan, Medical Officer of Health of Liverpool, 1847-63. London: H Hamilton Medical Books, 1947.

6 Obituary of E Headlam Greenhow. BM 1888;iv:1249-50.

7 Hodgkinson RG. The origins of the National Health Service: the medical services of the New Poor Law 1834-1871. London: The Wellcome Historical Medical Library, 1967
8 National Screening Committee. First report of the National Screening Committee. London: Health Departments of the United Kingdom, 1998.

9 Department of Health. Our healthier nation: a contract for health. London: The Stationery Office, 1998.

10 Social Exclusion Unit. Bringing Britain together : a national strategy for neighbourhood renewal. London: The Stationery Office, 1998.

11 Webster C. Peacetime history-the Health Services since the war. Vol 1. London: HMSO, 1988:15.

12 Fisher B, Neve H, Heritage Z. Community development, user involvement, and primary health care. BN 1999;318:749-50.

13 Gray JAM. Evidence-based healthcare. 2nd edn. Edinburgh: Churchill Livingstone, 2001.

14 Donaldson LJ. Medical mishaps: a managerial perspective. In: Rosenthal M, Mulcahy L, Lloyd-Bostock S, eds. Medical mishaps: pieces of the puzzle. Buckingham, Open University Press, 1999.

15 NHS Executive South Thames. Review of cervical screening services at Kent and Canterbury Hospitals. London: NHS Executive, 1997.

16 Department of Health. The new NHS: modern and dependable. London: The Stationery Office, 1997. (Cm 3807)

17 Department of Health. A first class service: quality in the new NHS. London: Department of Health, 1998.

18 Donaldson LJ. Clinical governance: a new statutory duty for quality. $J$ Epidemiol Community Health 1998;52:73-4.

19 Department of Health. The new NHS modern and dependable primary care groups delivering the agenda. London: Department of Health, 1998. (Health Service Circular: HSC (98)228).

20 Cochrane AL. Effectiveness and efficiency. Random reflections on health services. London: Nuffield Provincial Hospitals Trust, 1972.

21 Smolan R, Moffit P. Medicine's great journey: one hundred years of healing. Introduction by Robert Coles. New York: New York Graphic Society, 1992.

22 Stiller C, Draper G. The epidemiology of cancer in children. In: Voute PA, Kalisa C, Barrett A, eds. Cancer in clinical management. Oxford: Oxford University Press, 1998.

23 Lambert R. Sir John Simon 1816-1904 and English social administration. London: MacGibbon and Kee, 1963 